\title{
Controversies in Fistula in Ano
}

\author{
Parvez Sheikh
}

Received: 1 May 2012 / Accepted: 15 May 2012 / Published online: 29 June 2012

(C) Association of Surgeons of India 2012

\begin{abstract}
Managing a complex fistula in ano can be a daunting task for most surgeons; largely due to the two major dreaded complications-recurrence \& fecal incontinence. It is important to understand the anatomy of the anal sphincters \& the aetiopathological process of the disease to provide better patient care. There are quite a few controversies associated with fistula in ano \& its management, which compound the difficulty in treating fistula in ano. This article attempts to clear some of those major controversies.
\end{abstract}

Keywords Fistula in ano $\cdot$ Anal fistula

\section{High Fistulas Have High Internal Openings}

More than $90 \%$ of all fistulas are caused by cryptoglandular infection [1]. The crypt is located at the pectinate line; thus the internal opening of the fistula, which corresponds to the opening of the duct at the crypt, is always at the level of the pectinate line. The sepsis may spread above the anorectal ring, but the internal opening is always at the pectinate line. One can have a high secondary internal opening at the site where a high inter-sphincteric fistula has ruptured intra-anally or a secondary opening has been created iatrogenically at a previous surgery. Fistulas caused by Crohns disease or other causes can have a high primary internal opening.

\footnotetext{
P. Sheikh

Saifee Hospital,

Mumbai, India

P. Sheikh $(\bowtie)$

Nova Specialty Center,

Mumbai, India

e-mail: parvez_sheikh@hotmail.com
}

\section{Internal Opening is Not Always Present}

By virtue of its definition, a fistula in ano has to have an internal opening - it is another matter that it may not be possible to locate the internal opening in a few cases. If the internal opening is blocked, the radiologist may report it as a sinus \& not a fistula, which is actually not true. If one cannot locate the internal opening in the clinic, a hydrogen peroxide enhanced ultrasound may be able to identify it. Majority of the previously unidentified internal opening can be identified under anesthesia - one needs to look in the midline at the pectinate line for it.

\section{Fistulas with Multiple Openings are Tuberculus in Origin}

It was earlier thought that fistulas with multiple openings were most probably tuberculus in origin \& empirical antituberculus treatment (ATT) was given to these patients. The histology of these types of fistulas usually do not reveal tuberculosis (Figs. 1 and 2). The multiple openings on one side of the anal canal are interconnected subcutaneously, \& are representative of the sepsis spreading subcutaneously, when the existing external opening gets sealed off. No ATT should be given unless there is radiological or histological proof of active tuberculus disease.

\section{Every Fistula Requires an MRI/Endoanal USG}

Investigations in fistula in ano are additional tools available to the surgeon in case of difficulty. They do not replace a good clinical examination to diagnose the type \& extent of fistula. It is not necessary to investigate every case of fistula 


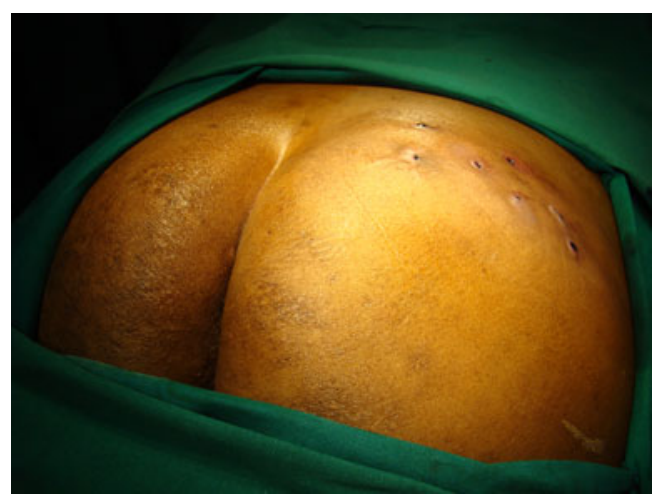

Fig. 1 Mutiple external openings over the right buttock-non tuberculus

in ano; even the complex ones can be diagnosed fairly accurately by a good clinical examination. MRI \& Endoanal ultrasound both give comparable results [1] (Fig. 3). Delineating the tracts by intra-operative dye study may be more helpful than the above investigations. Fistulograms have a very limited role in the diagnosis of fistula in ano.

\section{Whether Ano-rectal Abscess Should be Just Drained or Treated Like a Fistula?}

All fistulas essentially start as abscesses, which may either rupture spontaneously or may need a surgical drainage (Fig. 4). Almost one third of all abscesses develop a fistula. Abscesses caused by gut organism like E. coli \& Bacteroides are more likely to develop a fistula, rather than those caused by skin organism like staphylococcus or streptococcus [2]. There has been much controversy whether all abscesses should be treated like fistula to lower recurrence rate. In a Cochrane database published in 2010 [3], six trials were identified, involving 479 subjects, comparing incision and drainage of perianal abscess alone versus incision and drainage with fistula treatment. The authors concluded that

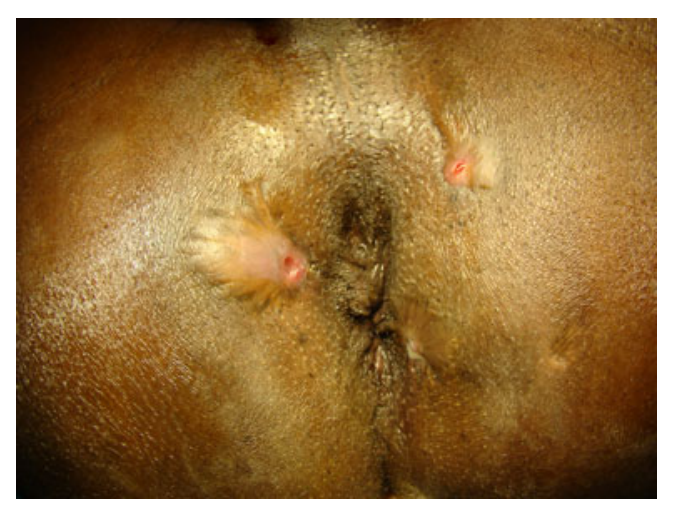

Fig 2 Horseshoe fistula in ano

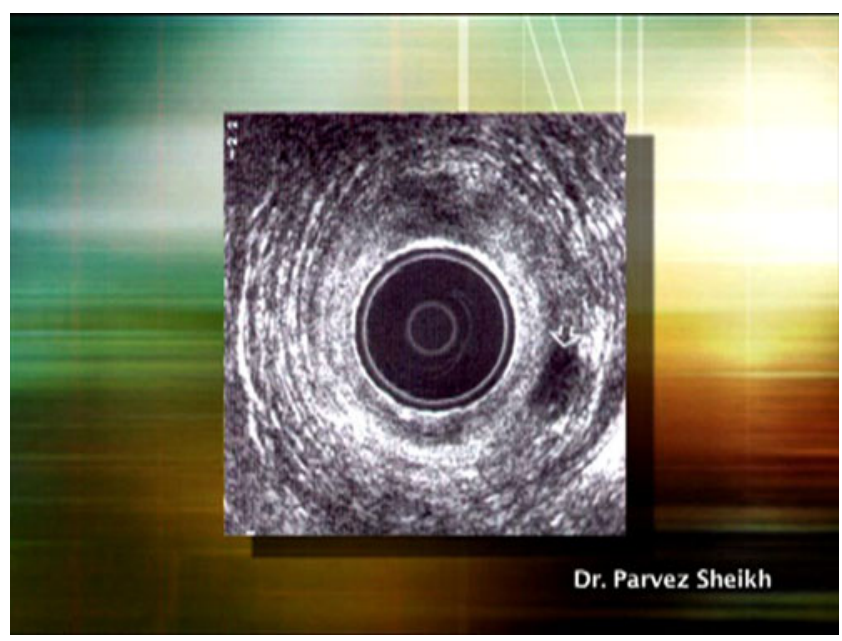

Fig 3 Endoanal USG showing an iner-sphincteric abscess

fistula surgery with abscess drainage significantly reduces recurrence or persistence of abscess/fistula, or the need for repeat surgery. There was no statistically significant evidence of incontinence following fistula surgery with abscess drainage. Thus primary surgery for fistula along with drainage of the abscess can be recommended as the preferred surgery to those surgeons who have sufficient experience in treating fistulas, provided the patients' general condition \& local anatomical circumstances are favorable [4]. Perianal abscesses have a lower incidence of developing a fistula as compared to ischioanal abscesses.

\section{Which is the Best Surgery for Fistula in Ano?}

There are many options to treat fistula in ano; new options are being added each year. Fistulotomy or fistulectomy involves division of the underlying sphincter tissue $\&$ is generally recommended for low fistulas. However, sphincter-preserving treatment may be advocated for patients with low preoperative voluntary contraction

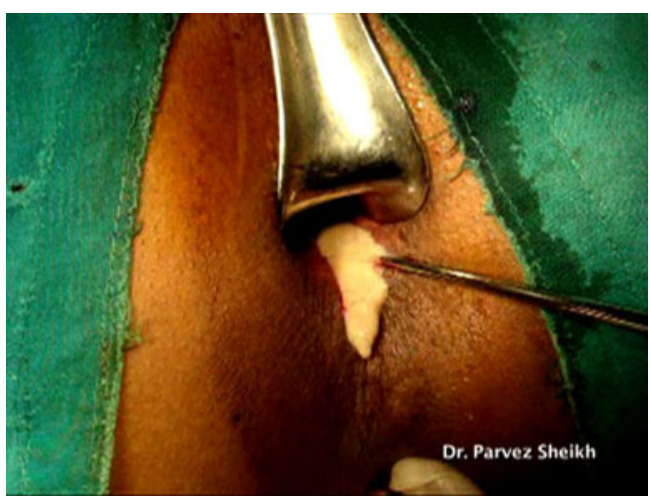

Fig 4 Pus pouring through the internal opening of an inter-sphincteric abscess 
pressure or those who have undergone multiple drainage surgeries [5]. Fistulectomy with primary sphincter reconstruction can improve both anal continence and manometric values in incontinent patients, without compromising them in fully continent ones [6].

In 2005, David Armstrong described the anal fistula plug which was derived from the submucosa of the porcine small intestine. His initial results showed a success rate of $83 \%$ [7]. The high success rate of David Armstrong could not be replicated by most others \& various published data has shown success rates varying from $29 \%$ to $53 \%$. The results with the plug have been comparable or inferior to the advancement flap. The plug may however be useful in Crohn's fistulas, where it may be considered as an alternative treatment, although the success rate even in these cases is low [8-11]. Some studies have shown that longer tracts have better chances of closure [12]. Results with bioprosthetic plugs have shown higher results varying from $54 \%$ to $72 \%$, although the test series have been very small [13-15].

Seton is the preferred treatment for fistula in the west as it is a less radical approach with minimal damage to the sphincter. However the main disadvantage is the prolonged period required for wound healing \& the discomfort caused to the patient during that time [16]. The preferred method of using a seton is to use it as a "draining" seton rather than a "cutting" seton. Although a cutting seton can have better success rate as high as $99 \%$ [17], it can cause severe discomfort to the patient \& can have an incidence of incontinence as high as $18 \%-25 \%[18,19]$. Draining seton can have a persistent fistula rate ranging between $20 \%$ and $40 \%$, but with a low incidence of incontinence. It may be the preferred surgical treatment of choice in Crohns fistula, but with a recurrence rate as high as $40 \%[20,21]$.

Advancement flaps have a success rate between $48 \%$ and $62 \%$. The flap should consist of the mucosa \& part of the internal sphincter, should have a broad base with good blood supply \& should be sutured without tension. The success rate can be improved by excising the underlying infected anal gland \& curetting the rest of the tract. The results are comparable to anal fistula plug. Combining plug with advancement flap will further increase the success rate. Though fibrin glue has been widely used, the high recurrence rates associated with using it as primary treatment for fistula, does not make it as a favorable method of treatment.

In 2007, Dr. Arun Rojanasakul first published an article on a total sphincter saving procedure which he termed as L.I.F.T. (ligation of inter-sphincteric fistula tract) [22]. Subsequent studies have revealed an healing rate ranging from $68 \%$ to $83 \%$ with an average healing time from 6 to 7 weeks [23-26]. Since it is a sphincter sparing procedure, LIFT has now become a very popular surgery worldwide.

VAAFT (Video assisted anal fistula treatment) first described by Prof. Meinero, is done with the help of a rigid endoscope. The tract is cauterized, curetted \& the internal opening is stapled. This technique is relatively new $\&$ can be performed only in some types of fistula. As yet not much data is available about this technique

Cochrane database in 2010 by Jacob TJ et al. have concluded that there seems to be no major difference between the various techniques used as far as recurrence rates are concerned. The use of fibrin glue and advancement flaps are associated with low incontinence rates. There is a crying need for well powered, well conducted randomized controlled trials comparing various modes of treatment of fistula in ano. Newer operations like the anal fistula plug and the LIFT procedure need to be evaluated by randomized clinical trials [27]. Thus there is no single method that is ideal \& one has to choose the surgery depending on his/her experience, the type of fistula \& the other local conditions.

\section{References}

1. Ommer A, Herold A, Berg E, Fürst A, Sailer M, Schiedeck T (2011) Cryptoglandular anal fistulas. Dtsch Arzteblatt Int 108 (42):707-713. doi:10.3238/arztebl.2011.0707, Epub 2011 Oct 21

2. Toyonaga T, Matsushima M, Tanaka Y, Shimojima Y, Matsumura N, Kannyama H, Nozawa M, Hatakeyama T, Suzuki K, Yanagita K, Tanaka M (2007) Microbiological analysis and endoanal ultrasonography for diagnosis of anal fistula in acute anorectal sepsis. Int J Colorectal Dis 22(2):209-213, Epub 2006 Apr 7

3. Malik AI, Nelson RL, Tou S (2010) Incision and drainage of perianal abscess with or without treatment of anal fistula. Cochrane Database Syst Rev (7):CD006827

4. Holzheimer RG, Siebeck M (2006) Treatment procedures for anal fistulous cryptoglandular abscess - how to get the best results. Eur J Med Res 11(12):501-515

5. Toyonaga T, Matsushima M, Kiriu T, Sogawa N, Kanyama H, Matsumura N, Shimojima Y, Hatakeyama T, Tanaka Y, Suzuki K, Tanaka M (2007) Factors affecting continence after fistulotomy for intersphincteric fistula-in-ano. Int J Colorectal Dis 22(9):10711075, Epub 2007 Jan 30

6. Perez F, Arroyo A, Serrano P, Candela F, Perez MT, Calpena R (2006) Prospective clinical and manometric study of fistulotomy with primary sphincter reconstruction in the management of recurrent complex fistula-in-ano. Int J Colorectal Dis 21(6):522-526, Epub 2005 Oct 20

7. Champagne BJ, O'Connor LM, Ferguson M, Orangio GR, Schertzer ME, Armstrong DN (2006) Efficacy of anal fistula plug in closure of cryptoglandular fistulas: long-term follow-up. Dis Colon Rectum 49(12):1817-1821

8. Wang JY, Garcia-Aguilar J, Sternberg JA, Abel ME, Varma MG (2009) Treatment of transsphincteric anal fistulas: are fistula plugs an acceptable alternative? Dis Colon Rectum 52(4):692-697

9. Schwandner O, Stadler F, Dietl O, Wirsching RP, Fuerst A (2008) Initial experience on efficacy in closure of cryptoglandular and Crohn's transsphincteric fistulas by the use of the anal fistula plug. Int J Colorectal Dis 23(3):319-324, Epub 2007 Nov 22

10. van Koperen PJ, Bemelman WA, Gerhards MF, Janssen LW, van Tets WF, van Dalsen AD, Slors JF (2011) The anal fistula plug treatment compared with the mucosal advancement flap for cryptoglandular high transsphincteric perianal fistula: a double-blinded multicenter randomized trial. Dis Colon Rectum 54(4):387-393 
11. Lupinacci RM, Vallet C, Parc Y, Chafai N, Tiret E (2010) Treatment of fistula-in-ano with the Surgisis $\left({ }^{\circledR}\right)$ AFP(TM) anal fistula plug. Gastroenterol Clin Biol 34(10):549-553, Epub 2010 Sep 6

12. McGee MF, Champagne BJ, Stulberg JJ, Reynolds H, Marderstein E, Delaney CP (2010) Tract length predicts successful closure with anal fistula plug in cryptoglandular fistulas. Dis Colon Rectum 53 (8):1116-1120

13. Ratto C, Litta F, Parello A, Donisi L, Zaccone G, De Simone V (2012) Gore Bio-A $\left({ }^{\circledR}\right)$ fistula plug, a new sphincter-sparing procedure for complex anal fistula. Colorectal Dis. doi:10.1111/j.14631318.2012.02964.x

14. Han JG, Wang ZJ, Zhao BC, Zheng Y, Zhao B, Yi BQ, Yang XQ (2011) Long-term outcomes of human acellular dermal matrix plug in closure of complex anal fistulas with a single tract. Dis Colon Rectum 54(11):1412-1418

15. Buchberg B, Masoomi H, Choi J, Bergman H, Mills S, Stamos MJ (2010) A tale of two (anal fistula) plugs: is there a difference in short-term outcomes? Am Surg 76(10):1150-1153

16. Lentner A, Wienert V (1996) Long-term, indwelling setons for low transsphincteric and intersphincteric anal fistulas. Experience with 108 cases. Dis Colon Rectum 39(10):1097-1101

17. Chuang-Wei C, Chang-Chieh W, Cheng-Wen H, Tsai-Yu L, ChunChe F, Shu-Wen J (2008) Cutting seton for complex anal fistulas. Surgeon 6(3): 185-188

18. Ritchie RD, Sackier JM, Hodde JP (2009) Incontinence rates after cutting seton treatment for anal fistula. Colorectal Dis 11(6):564571, Epub 2008 Oct 17

19. Vial M, Parés D, Pera M, Grande L (2010) Faecal incontinence after seton treatment for anal fistulae with and without surgical division of internal anal sphincter: a systematic review. Colorectal Dis 12(3):172-178, Epub 2009 Feb 7
20. Galis-Rozen E, Tulchinsky H, Rosen A, Eldar S, Rabau M, Stepanski A, Klausner JM, Ziv Y (2010) Long-term outcome of loose seton for complex anal fistula: a two-centre study of patients with and without Crohn's disease. Colorectal Dis 12(4):358-362, Epub 2009 Feb 7

21. Eitan A, Koliada M, Bickel A (2009) The use of the loose seton technique as a definitive treatment for recurrent and persistent high trans-sphincteric anal fistulas: a long-term outcome. J Gastrointest Surg 13(6):1116-1119, Epub 2009 Feb 24

22. Rojanasakul A, Pattanaarun J, Sahakitrungruang C, Tantiphlachiva K (2007) Total anal sphincter saving technique for fistula-in-ano; the ligation of intersphincteric fistula tract. J Med Assoc Thai 90 (3):581-586

23. Aboulian A, Kaji AH, Kumar RR (2011) Early result of ligation of the intersphincteric fistula tract for fistula-in-ano. Dis Colon Rectum 54(3):289-292

24. Shanwani A, Nor AM, Amri N (2010) Ligation of the intersphincteric fistula tract (LIFT): a sphincter-saving technique for fistulain-ano. Dis Colon Rectum 53(1):39-42

25. Sileri P, Franceschilli L, Angelucci GP, D’Ugo S, Milito G, Cadeddu F, Selvaggio I, Lazzaro S, Gaspari AL (2011) Ligation of the intersphincteric fistula tract (LIFT) to treat anal fistula: early results from a prospective observational study. Tech Coloproctol 15(4):413-416, Epub 2011 Nov 11

26. Ooi K, Skinner I, Croxford M, Faragher I, McLaughlin S (2011) Managing fistula-in-ano with ligation of the intersphincteric fistula tract (LIFT) procedure: the Western Hospital experience. Colorectal Dis. doi:10.1111/j.1463-1318.2011.02723.x

27. Jacob TJ, Perakath B, Keighley MR (2010) Surgical intervention for anorectal fistula. Cochrane Database Syst Rev (5): CD006319 